In our study five of six index children ( $38 \%$ of families) who presented with motor or psychomotor delay could have been diagnosed if all children who had not walked by the age of 18 months had had their creatine kinase activity estimated, as suggested by GardnerMedwin. ${ }^{3}$ A further seven (44\% of families) presented with clumsiness of gait or excessive falling. Diagnosis in such cases requires familiarity with the typical Duchenne waddle and abnormal consistency of the calf muscles. Finally, no doctor should do or recommend Achilles tendon lengthening operations until the aetiology is firmly established. Against a background of a relatively rare but important disease-whose prevalence of $3 / 100000$ means that a considerable number of family practitioners will have no case on their panels-a series of well designed circulars sent to all relevant practitioners, together with financial support for attendance at clinical demonstrations, could provide a real and inexpensive alternative to a newborn screening programme. Such a programme would also circumvent the problem of causing unnecessary distress to parents by diagnosing an incurable disease in the neonatal period. ${ }^{3}$

We thank the Muscular Dystrophy Group of Great Britain for their support.

Zellweger H, Antonik A. Newborn screening for Duchenne muscular dystrophy. Pediatrics 1975;55:30-4.

${ }^{2}$ Anonymous. Screening of the newborn for Duchenne muscular dystrophy. Br Med F 1975 ;ii :403-4.

${ }^{3}$ Gardner-Medwin D. Controversies about Duchenne muscular dystrophy. Dev Med Child Neurol 1979;21:390-3.

4 Harper PS, O'Brien T, Murray JM, Davies KE, Pearson PL, Williamson R. The use of linked DNA polymorphisms for genotype prediction in families with Duchenne muscular dystrophy. $\mathcal{F}$ Med Genet 1983;20: 252-4.

5 O'Brien T, Harper PS, Davies KE, Murray JM, Sarfarazi M, Williamson R. Absence of genetic heterogeneity in Duchenne muscular dystrophy shown by a linkage study using two cloned DNA sequences. $7 \mathrm{Med}$ Genet $1983 ; 20: 249-51$

(Accepted 17 fune 1983)

Welsh National School of Medicine, Heath Park, Cardiff

T O'BRIEN, MRCP, DCH, senior registrar in medical genetics and child health

I R SIBERT, $M D, D C H$, consultant paediatrician

P S HARPER, MD, FRCP, professor and consultant in medical genetics

Correspondence and requests for reprints to: $\mathrm{Dr} \mathrm{T}$ O'Brien, Consultant Paediatrician, Bon Secours Hospital, Tralee, Ireland.

\section{Plasma prolactin concentrations in a large population of healthy old people}

The physiological importance of the change in dopaminergic mechanisms during aging has been clearly established. In both animals and man the function of presynaptic and postsynaptic dopaminergic mechanisms is altered during later life with a considerable decrease in synthesis and receptor function. ${ }^{1-4}$ In vivo measurement of dopaminergic function in man is difficult owing to the lack of variables that accurately reflect such function. Although plasma prolactin concentrations reflect the result of various neuronal interactions, dopamine is thought to exert an important inhibitory control on release of prolactin. Thus an age dependent reduction of dopaminergic function in the tuberoinfundibular system might induce an increase of plasma prolactin concentrations. We carried out a study to investigate this.

\section{Subjects, methods, and results}

We have carried out a large scale study of a homogeneous population of elderly people in the small town of Ome (Lombardy, northern Italy), studying the general health of the inhabitants aged over 59 and checking certain clinical and biochemical variables indicative of specific diseases.

We measured plasma prolactin concentrations in 260 old people. Blood was collected from the brachial vein between 0700 and 0900 always in the same environment and by the same medical team. Prolactin concentrations were measured by radioimmunoassay using a commercial kit (Amersham
International, England). No evidence of endocrinological or neuropsychiatric disease was detected.

Among women plasma prolactin concentrations were significantly higher in those aged 74-78 and those aged 79 and over than in those aged 59-63 (table), and a significant correlation was found between age and plasma prolactin concentrations $(p<0.05)$. By contrast, no age related differences were observed in the men. Surprisingly, the mean plasma prolactin concentration in the men as a whole was the same as that in the women, although in younger people (aged below 45) concentrations are lower in men.

Correlation between age and mean (SD) plasma prolactin concentrations in healthy old people

\begin{tabular}{|c|c|c|c|c|}
\hline \multirow{2}{*}{$\begin{array}{l}\text { Age group } \\
\text { (years) }\end{array}$} & \multicolumn{2}{|l|}{ Women } & \multicolumn{2}{|l|}{ Men } \\
\hline & Prolactin (ng/ml) & $\mathbf{n}$ & Prolactin (ng/ml) & $\mathbf{n}$ \\
\hline $\begin{array}{c}59-63 \\
64-68 \\
69-73 \\
74-78 \\
\geqslant 79\end{array}$ & $\begin{array}{c}7.91(3.96) \\
9.30(4.72) \\
9.00(4.13) \\
10.15(5.01)^{*} \\
10.36(3.58)^{*}\end{array}$ & $\begin{array}{l}53 \\
30 \\
33 \\
21 \\
13\end{array}$ & $\begin{array}{c}10.41(5.20) \\
10.21(4.55) \\
9.03(4.42) \\
8.80(2.05) \\
9.10(2.95)\end{array}$ & $\begin{array}{r}34 \\
29 \\
32 \\
10 \\
5\end{array}$ \\
\hline
\end{tabular}

*p $<0.05$ compared with women aged 59-63 (two tailed Student's $t$ test).

\section{Comment}

It is possible that the inhibitory dopaminergic control on secretion of prolactin in the men had already reached a plateau at earlier ages. In contrast, it is possible that in women the dopaminergic control of secretion of prolactin becomes more important at the end of the fertile period. After this period the derangement of dopaminergic transmission leads to a small but important increase in secretion of prolactin.

The significant increase in plasma prolactin concentration detected confirms the hypothesis that dopaminergic function is decreased in older women. The increased incidence of breast tumours observed at this age may depend on the changes in plasma prolactin concentrations. The data also indicate that a mild dopaminomimetic drug may be useful in treating the typical disturbances induced by aging.

${ }^{1}$ Govoni S, Loddo P, Spano PF, Trabucchi M. Dopamine receptor sensitivity in brain and retina of rats during ageing. Brain Res 1977; 138:565-9.

${ }^{2}$ Finch CE. Catecholamine metabolism in the brain of ageing male mice. Brain Res 1973;52:261-76.

3 Trabucchi M, Spano PF, Govoni S, Riccardi F, Bosio A. Dopaminergic function during aging in rat brain. In: Giacobini E, Filogano G, Vernadakis A, eds. Aging. Vol 20. New York: Raven Press, 1982: 195-201.

${ }^{4}$ Cotzias GC, Miller ST, Tang LC, Papavasiliou PS, Wang YY. Levodopa, fertility and longevity. Science 1977;196:549-51.

(Accepted 7 fune 1983)

Institute of Pharmacology and Therapeutics, University of Brescia, 25100 Brescia, Italy

S GOVONI, PHD, assistant professor of pharmacology

G PASINETTI, MD, consultant physician

M TRABUCCHI, MD, chief, department of pharmacology

Long Term Care Ward, S Orsola Hospital, Brescia

M R INZOLI, MD, chief, long term care ward

R ROZZINI, MD, assistant, long term care ward

Correspondence to: Dr S Govoni.

\section{Morbidity in diabetic and non-diabetic patients after major vascular surgery}

Postoperative morbidity is generally thought to be higher in diabetics, ${ }^{12}$ but there are no reports of studies that have included matched non-diabetic controls. We carried out a study to investigate postoperative morbidity in diabetics undergoing major vascular surgery and in non-diabetic controls matched for type of surgery, age, sex, weight, and complicating diseases. 


\section{Patients, methods, and results}

We reviewed the records of 64 consecutive diabetic patients who had undergone elective aortoiliac or femoral bypass (43 patients) or aortoiliac thromboendarterectomy (21) from January 1975 to July 1982 . From the 1236 non-diabetic patients who had undergone the same operations within the same period we selected 64 patients at random without knowledge of postoperative morbidity but matched to the diabetics for age (means 60 years (diabetics) and 57 years (non-diabetics)), sex (27 women and $37 \mathrm{men}$ ), and weight (mean $78 \mathrm{~kg}$ (diabetics) and $79 \mathrm{~kg}$ (non-diabetics)). Similar numbers of diabetics and controls had heart failure (25 and 21 respectively), angina pectoris (12 and 11), and hypertension (12 and 13). Twenty three diabetic patients compared with 18 controls were treated with digoxin. Diuretics were used in 26 diabetics and 19 controls. Beta-blockers were taken by 11 diabetics and eight controls. The degree of peripheral arteriosclerosis, as estimated from arteriograms, was similar in the two groups.

The average duration of diabetes was $10 \cdot 8$ years (range four to 18 years). Twenty three patients received insulin and 22 oral antidiabetic agents, and 19 were treated by diet. Two patients had severe retinopathy, five nephropathy, and 17 polyneuropathy. Postoperative treatment of the diabetics was based on results of four daily blood glucose tests.

All patients in both groups received prophylactic anticoagulation with phenprocoumon (Marcoumar) and antibiotics (penicillin and an aminoglycoside). The surgical procedures were similar in the two groups, and more than $95 \%$ were performed by the same three surgeons. Fisher's exact test was used to compare postoperative morbidity data in the two groups, and Student's $t$ test for unpaired data to compare blood glucose concentrations; probabilities below 0.05 were considered to be significant. Calculation of type II error was made according to Feinstein. ${ }^{3}$

The table gives data on postoperative morbidity. There was no difference in the total number of complications between the two groups ( 15 in the diabetic group (one patient with two complications) and 14 in the control group; $p>0.5$ ). The mean difference in the incidence of complications was $1.5 \%(95 \%$ confidence limits $-13 \%$ to $+16 \%)$.

Of the diabetics with complications, five received insulin and six oral antidiabetic agents, and three were treated by diet. There was no difference $(p>0.4)$ in postoperative blood glucose concentrations between diabetic patients with and without complications. Thus mean (SEM) fasting blood glucose concentrations before and $24,48,72$, and 96 hours after surgery were $7 \cdot 8(0 \cdot 4), 7 \cdot 1(0 \cdot 3), 8 \cdot 3(0.5), 8 \cdot 8(0 \cdot 8)$, and $9 \cdot 3(0.8) \mathrm{mmol} / 1(122(7 \cdot 2)$, $128(5 \cdot 4), 150(9), 159(14 \cdot 4)$, and $168(14 \cdot 4) \mathrm{mg} / 100 \mathrm{ml})$ in the diabetics with complications and $8 \cdot 1(0 \cdot 2), 7 \cdot 4(0.2), 8 \cdot 9(0.4), 8 \cdot 9(0 \cdot 3)$, and $8 \cdot 7$ $(0.4) \mathrm{mmol} / 1(146(3.6), 133(3.6), 160(7.2), 160(5.4)$, and $157(7.2) \mathrm{mg} /$ $100 \mathrm{ml})$ in those without complications.

The risk of overlooking a $25 \%$ difference (type II error) in the incidence of complications between diabetic and non-diabetic patients-that is, from the actual incidence of $22 \%$ to $28 \%$-was less than $20 \%$. The risk of overlooking a $50 \%$ increase in morbidity in the diabetic patients (from the actual $22 \%$ to $33 \%$ ) was less than $5 \%$

Postoperative complications after major vascular procedures in diabetic and non-diabetic patients (no deaths occurred)

\begin{tabular}{lll}
\hline & $\begin{array}{c}\text { Diabetics } \\
(\mathrm{n}=64)\end{array}$ & $\begin{array}{c}\text { Controls } \\
(\mathrm{n}=64)\end{array}$ \\
\hline $\begin{array}{l}\text { Wound infection } \\
\text { Venous thrombophlebitis }\end{array}$ & 4 & 3 \\
Pulmonary embolism & 1 & 1 \\
Septicaemia & & \\
Arterial or prosthetic thrombosis or embolism & 4 & 2 \\
Pneumonia & 4 & 4 \\
Urinary tract infection & 2 & 3 \\
Acute myocardial infarction & & 1 \\
\hline Total morbidity & $15(23.4 \%)$ & $14(21.9 \%)$ \\
\hline
\end{tabular}

\section{Comment}

We found no difference in the incidence of complications postoperatively between diabetic patients and matched controls. No correlation was found between the types of diabetes and the incidence of complications. Blood glucose concentrations were almost identical in diabetic patients with and without complications.

It might be argued that our study included too few patients for a significant difference in postoperative morbidity to be shown. Nevertheless, the risk of a type II error (overlooking a $50 \%$ or more difference in the incidence of postoperative complications) was less than $5 \%$ We therefore concluded that diabetics undergoing major vascular surgery do not have a greater risk of postoperative complications.

Our results support those of a recent retrospective study in which postoperative morbidity was similar in diabetic and matched nondiabetic control patients undergoing gallbladder surgery. ${ }^{4}$ There is thus some evidence against the common belief that diabetes mellitus is associated with increased postoperative morbidity, but studies of other surgical procedures are needed.

${ }^{1}$ Cruse PJE, Ford R. A five year prospective study of 23649 surgical wounds. Arch Surg 1973;107:206-11.

${ }^{2} \mathrm{Kahn}$ O, Wagner W, Bessman AN. Mortality of diabetic patients treated surgically for lower limb infection and/or gangrene. Diabetes $1974 ; 23$ : 287-92.

${ }^{3}$ Feinstein AR. Clinical biostatistics. XXXIV. The other side of "statistical significance": alpha, beta, delta and the calculation of sample size. Clin Pharmacol Ther 1975;18:491-505.

* Walsh DB, Eckhauser FE, Ramsburgh SR, Burney RB. Risk associated with diabetes mellitus in patients undergoing gall bladder surgery. Surgery $1982 ; 91: 254-7$.

(Accepted 15 fune 1983)

Department of Vascular Surgery D, Rigshospitalet, Copenhagen, Denmark

ALLAN HJORTRUP, MD, senior registrar

BO FELDT RASMUSSEN, MD, registrar

HENRIK KEHLET, MD, senior registrar

Correspondence to: Dr A Hjortrup, Akacievej 27, 2791 Dragør, Denmark.

\section{Sciatic neuropathies}

Most reports on sciatic neuropathies record wartime experience. ${ }^{1}$ We have reviewed the causes of sciatic nerve lesions in an urban peacetime setting.

\section{Present study and results}

All the patients were seen in the electromyography laboratory of a large general hospital for evaluation of leg weakness. Each was examined by neurologist and underwent nerve conduction and electromyographic studies.

Thirty nine electrophysiologically confirmed sciatic neuropathies were detected in 34 patients. The table summarises the causes.

Sciatic neuropathies: causes in 34 patients

External compression (four patients had bilateral neuropathies) No of patients Hip fracture-dislocations

Hip surgery

Miscellaneous (one patient had bilateral neuropathies) $\quad \cdots \quad$.

External compression (10 patients)-Five patients developed sciatic neuropathies after an episode of coma resulting from an overdose of drugs or alcohol or both. Two patients had prolonged coma after a head injury and their bilateral neuropathies resulted from being bedridden for many weeks. One patient developed bilateral sciatic nerve compression after an eight hour operation in the sitting position. One patient worked for a long time in a cramped position with his buttock against a sharp edge.

Hip fracture-dislocations (10 patients)-The typical injury was a hip fracture including the posterior acetabulum. The commonest cause was a motor vehicle accident.

Hip surgery (six patients)-Five patients had had total hip replacements and one a Chiari type pelvic osteotomy.

Direct trauma (four patients)-These patients had suffered direct injuries to the thighs, but only one had a fractured femur.

Miscellaneous (four patients)-One patient had endometriosis at the sciatic notch, compressing the sciatic and inferior gluteal nerves. Another developed compression at this site from a haematoma resulting from anticoagulation treatment for a pulmonary embolus after a hip replacement. In only one patient (with bilateral sciatic neuropathies) were the lesions due to injections. One patient had a sciatic neuropathy as part of a mononeuritis multiplex syndrome of unknown aetiology.

\section{Comment}

In war missile injuries account for most sciatic nerve lesions. ${ }^{12}$ In our peacetime experience trauma is also the single commonest cause, particularly fracture-dislocations of the hip resulting from motor vehicle accidents. Sciatic neuropathies due to fractures of the shaft of the femur are considerably less common. The second commonest 